\title{
DEVELOPMENT AND APPLICATION OF THE KEY TECHNOLOGIES FOR THE QUALITY CONTROL AND INSPECTION OF NATIONAL GEOGRAPHICAL CONDITIONS SURVEY PRODUCTS
}

\author{
ZHAO Yousong ${ }^{1}$, ZHANG Li ${ }^{1}$, MA Wei ${ }^{1}$, ZHANG Pengcheng ${ }^{1}$, ZHAO Tingting ${ }^{2}$ \\ ${ }^{1}$ National Quality Inspection and Testing Center for Surveying and Mapping Products, Beijing 100830, China \\ ${ }^{2}$ National Geomatics Center of China, Beijing 100830, China
}

\begin{abstract}
KEY WORDS: Geographical Condition Survey, Quality Control, Quality Inspection and Testing, Total Quality Control Target, Survey Products
\end{abstract}

\begin{abstract}
:
The First National Geographical Condition Survey is a predecessor task to dynamically master basic situations of the nature, ecology and human activities on the earth's surface and it is the brand-new mapping geographic information engineering. In order to ensure comprehensive, real and accurate survey results and achieve the quality management target which the qualified rate is $100 \%$ and the yield is more than $80 \%$, it is necessary to carry out the quality control and result inspection for national geographical conditions survey on a national scale. To ensure that achievement quality meets quality target requirements, this paper develops the key technology method of "five-in-one" quality control that is constituted by "quality control system of national geographical condition survey, quality inspection technology system, quality evaluation system, quality inspection information management system and national linked quality control institutions" by aiming at large scale, wide coverage range, more undertaking units, more management levels, technical updating, more production process and obvious regional differences in the national geographical condition survey and combining with novel achievement manifestation, complicated dependency, more special reference data, and large data size. This project fully considering the domestic and foreign related research results and production practice experience, combined with the technology development and the needs of the production, it stipulates the inspection methods and technical requirements of each stage in the quality inspection of the geographical condition survey results, and extends the traditional inspection and acceptance technology, and solves the key technologies that are badly needed in the first national geographic survey.
\end{abstract}

\section{INTRODUCTION}

The first national geographical condition survey is a major national condition and strength survey deployed by the State Council. It is a predecessor task to dynamically master basic situations of the nature, ecology and human activities on the earth's surface and it is the brand-new mapping geographic information engineering assumed by National Administration of Surveying, Mapping and Geoinformation of China. Survey quality determines its success or failure and concerns long-term development and upgrading of surveying, mapping and geoinformation undertakings. In order to ensure comprehensive, real and accurate survey results and achieve the quality management target which the qualified rate is $100 \%$ and the yield is more than $80 \%$, it is necessary to carry out the quality control and result inspection for national geographical conditions survey on a national scale. To ensure that achievement quality meets quality target requirements, this paper develops the key technology method of "five-in-one" quality control that is constituted by "quality control system of national geographical condition survey, quality inspection technology system, quality evaluation system, quality inspection information management system and national linked quality control institutions".

\section{CHARACTERISTICS OF THE METHOD}

To ensure that achievement quality meets quality target requirements, this paper develops the key technology method by aiming at large scale, wide coverage range, more undertaking units, more management levels, technical updating, more production process and obvious regional differences in the national geographical condition survey and combining with novel achievement manifestation, complicated dependency, more special reference data, and large data size.

Beginning from the national geographic census quality system top-level design, this project constructs the comprehensive and hierarchical quality control system and supervision mechanism, formulates quality management rules, develops the quality inspection standards, and develops the hierarchical sampling technology based on achievement types, regional features and production arrangement.

It is the first time for the project to develop the rapid quality inspection algorithm for trans-type national geographic census achievement data under the big data environment, as well as the quality inspection technology method based on multi-software combination. In addition, this project firstly proposes the national geographic census operator quality inspection and evaluation index system and quality evaluation standards of integrated weighting and error rate.

It is the first time for the project to construct the national geographic census achievement quality inspection informatization management system integrating with management, inspection and evaluation.

It is the first time for the project to construct the major engineering project quality inspection management mode and diversified quality control mechanism of national linkage and the project develops an important role on nationwide "process quality control, achievement acceptance inspection, achievement quality rechecking”. 


\section{KEY TECHNOLOGY AND INNOVATION}

3.1 It constructs the national geographical condition survey quality control system with national uniform linkage and overall hierarchical management, develops the first national geographical condition survey quality management rules, develops the survey products quality inspection evaluation standards, and unifies the top-level design for national geographical condition survey quality inspection. It has constructed the quality responsibility system of national censuses composed of quality management and inspection organizations at all levels.

The study defines the national geographic census quality management principles of national uniform linkage and overall hierarchical management. In order to construct the scientific national geographic census quality supervision management system, this study defines the quality management organization implementation principles of "national uniform leadership, local classification responsibility and co-participation of each party" and "uniform inspection standards, overall hierarchical management and scientific quality evaluation". By aiming at the national geographic census achievement quality control features, it is the first time for the study to come up with and construct the achievement quality control system based on inspection system, inspection standards, process control, control institutions and acceptance mechanism.

This study construct the national geographic census quality responsibility system constituted by quality management and inspection organizations at all levels. In order to safeguard integrity and accuracy of national geographic census achievements and ensure realization of national geographic census quality management targets, this study constructs the multi-level diversified management responsibility system composed of (provincial) census office of State Council, quality control technical support units, and quality inspection organization institutions and defines the quality management, quality inspection institutions and quality responsibilities.

This study formulates the national geographic census achievement quality inspection acceptance and quality evaluation standards. On the basis of national geographic census quality inspection investigation analysis and trial, by fully considering national geographic census achievement production technology roadmap, quality control and classification achievement features and developing the existing national standards of digital mapping achievement quality testing, the study formulates the National Geographic Census Inspection Acceptance and Quality Evaluation Standards and standardizes the national geographic census achievement inspection acceptance and quality evaluation requirements, procedures, methods and indexes.

3.2 It constructs the national geographical condition survey quality inspection technology system adapting to the productive practice, defines the quality control technology and method based on quality problems, realizes the quality control of critical quality inspection process based on multisoftware joint inspection, and solves the critical problem of quality control and inspection.

The quality inspection sampling technology that scientifically, objectively and accurately embodies national geographic census achievement quality is updated. By combining with the national geographic census achievement features and internal and external quality inspection operation practice, this project makes innovations on the digital achievement quality inspection sampling method. It is the first time for the project to apply the hierarchical proportional random sampling method. In other words, the batch achievements are divided into different layers in line with different regional environments, types of difficulties, and topographical types. According to proportion of each layer, the simple random sampling method is used to extract the unit achievement. This not only improves the representative of samples and reduces the sampling errors, but also effectively avoids from the "excessive concentration or omission of quality characteristics" in the traditional simple random sampling.

The design proposes the quality control process based on quality problems and comprehensively improves the acceptance quality inspection capacity and efficiency. By aiming at tight achievement acceptance time and heavy tasks, in order to ensure high-efficient completion of achievement acceptance after updating and checking standard time points, it is the first time for the project to set up the pre-acceptance process in the national major engineering quality inspection and carry out quality pre-evaluation. By forward leading of quality pass and tracking quality problems, the project ensures timely correcting technical departure, excludes the major potential quality hazard, and continuously improves the final achievement quality. To make innovations on acceptance inspection technology routes, on the basis of conventional inspection technology method, this project designs the combined method of overall inspection, detailed sample inspection, general inspection out of samples, timely finds out quality problems of universality and tendentiousness, and effectively improves the inspection efficiency. In addition, this project sets up the quality rechecking process for qualified achievements as the necessary supplement of the acceptance process. it lives up to the effective connection with provincial achievement acceptance and national achievement storage inspection and plays a positive and critical role on strictly controlling quality pass, unifying national achievement acceptance scale, timely finding out quality problems in the acceptance stage, and continuously improving achievement quality.

The project realizes the critical quality inspection control based on multi-software joint inspection and ensures high-efficient and fair acceptance quality inspection. On the basis of abstract inspection rules, the project constructs the flexible inspection model, applies the quality inspection mechanism of "rulesinspection items-schemes", and develops the national geographic census achievement acceptance quality inspection software. The full automatization of the overall inspection dramatically improves the inspection efficiency, realizes the batch automation inspection or human-computer interaction inspection for spatial reference system, precision of attributes, logical consistency, and gridding quality, and realizes quality problem verification based on multi-software joint inspection. For the quality control features in the pre-acceptance and acceptance stages, the design proposes the different quality control contents, including emphasis achievements in preacceptance stage and technical design consistent, logical consistency control between achievement types, emphasis in acceptance stage, achievement database construction, basic statistics and supervision application in later period. 
3.3 It constructs the quality evaluation system that is suitable for auto-judgment of computers, element importance classification system and quality evaluation method of national geographical condition survey, autospace recording method of quality problems based on mistake and omission classification and symbolic library, and auto-evaluation tool based on quality inspection database, and realizes the unification between quality evaluation indexes and methods around the country. It develops the quality automatic evaluation tool based on quality inspection database, and realizes the integration of management and automatic evaluation of quality problem.

The national geographic census achievement element importance classification system and quality evaluation index system based on computer automatic identification are developed. Based on the current standard quality evaluation system, this project designs the importance classification system of extremely important elements, important elements and general elements for national geographic census classification achievements. This provides the necessary conditions for quality evaluation based on computer automatic identification and solves some problems that elements' importance classification system is not suitable for the surface coverage classification data and important national geographic element data by aiming at the traditional mapping achievement formulation in GB/T 18316-2008.

By combining with different types of national geographic census achievement features, according to achievement quality(sub)elements and inspection contents, on the basis of summarizing the process quality control and achievement preacceptance problem types, this study constructs the mistake and omission classification system of national geographic census achievements, designs the symbolic library of quality problem classification, develops the spatialization of inspection recording technology, develops the quality problems' auxiliary annotation system, and realizes the positioning retrieval and uniform management of quality problems.

This project develops the achievement quality automation evaluation tool based on quality problem database, realizes the integration between quality problems' spatial management and automation evaluation, ensures the reliability of quality evaluation and improves scientificity of quality problem analysis, tracking efficiency and quality evaluation.

3.4 It establishes the quality inspection information management system based on the database, constructs the quality inspection database of national linked geographical condition survey, sample database and inspection database based on the retrieval technique, realizes the linkage analysis for national quality problems, and lays a foundation on confirmation of quality inspection emphasis, inspection process setting and inspection efficiency improvement.

In quality inspection information management system, this project firstly constructs the national geographic census data informatization quality inspection system integrating with management, inspection and evaluation. By aiming at the current mapping geographic information quality inspection operation, manual first, and low automation degree, this project develops the national geographic census data informatization quality inspection technology system integrating with networked collaborative operation, real-time monitoring schedule status, automatic inspection, human-computer interaction inspection, quality inspection management and evaluation. It is the first time for the project to propose the quality inspection information classification management technology based on professional database and divides quality inspection information into project management, quality inspection, quality evaluation, user management and data. The database table management of different identification and coding rules is used to effectively safeguard the information integrity and inspection traceability of the entire quality inspection or inspection activity. It is the first time for the project to propose the integrated network communication technology, database technology, information technology and geographic information data quality theory and realize the integration management of national geographic census project, data, tasks, evaluation mode, quality inspection scheme, quality inspection, result output and quality evaluation.

3.5 It makes innovations on the quality inspection management mode of major project achievement acceptance, constructs the national linked diversified quality management mechanism, and sets up the "three-inone" quality control system based on process quality, achievement (pre)acceptance inspection and achievement quality rechecking.

The project makes innovations on quality control system, sets up the quality control system based on process quality control, achievement acceptance inspection, and achievement quality rechecking, and ensures that the national achievement quality satisfies the project management target requirements. It develops an important role on the national geographic quality inspection and provides reference for the quality control of other major mapping engineering projects.

The project constructs the quality control mode of national linkage, unifies quality standard and control process, quality evaluation index and method, and ensures that the overall achievement has the uniform quality level.

The project constructs the diversified quality control mechanism, forms the diversified control mechanism of uniform quality control institutions, quality training and technical consulting treatment, and ensures that quality problems can be disposed, solved and rectified timely and effectively..

\section{PRACTICAL APPLICATION EFFECTS}

4.1 Protect the national geographic census achievement quality control and inspection

This project fully considers relevant domestic and overseas research achievements and production practice experience and combines with urgent demands of technical development and production. Inspection methods and technical requirements in each stage in the national geographic census achievement quality inspection extend the traditional inspection and acceptance technology to the urgent key technology in the first national geographic census achievement inspection. The national geographic census achievement quality inspection acceptance and quality evaluation standards are widely used in the first national geographic census achievement quality inspection. It plays an important role on standardizing the national geographic census achievement quality inspection 
technology standards, improving the quality inspection efficiency, and guaranteeing the first national geographic census achievement quality, thus it receives the good reputation from each department and production unit, ensuring the realization of the first national geographic census quality management objectives around the country.

\subsection{Develop an important role on the census achievement acceptance inspection assumed by the Central Finance}

The quality control and inspection technology system developed by this project has been successfully applied in the census achievement acceptance inspection assumed by the Central Finance. The inspection ranges get involved in 227 administrative counties including Xinjiang, Tibet, Qinghai, Gansu and Yunnan, involved in 11001(1:50000) census achievements of 3.92 square kilometers. The acceptance inspection comprehensively applies the national census quality inspection software, inspection and quality evaluation technology developed by the project to form 26274 spatialization inspection records, 2660 quality evaluation tables, and 48 inspection reports, realizing $100 \%$ of yield and $100 \%$ excellent rate.

\subsection{Play a crucial role in the national geographic census} achievement quality rechecking

The quality control and inspection technology system developed by this project has been successfully applied in the first national geographic census achievement quality rechecking. The rechecking ranges get involved in 5.7 square kilometers of census achievement in 31 provinces. The rechecking inspection process applies the inspection mode and method of spatialization inspection records and quality evaluation integration, uniform quality inspection templates and quality evaluation principles of important elements to recheck 9628(1:10000) census achievements, form 9628 recording tables for filing, and 31 rechecking reports, and realize $100 \%$ yield and $95 \%$ of excellent rate.

\section{CONCLUSIONS}

This project fully considering the domestic and foreign related research results and production practice experience, combined with the technology development and the needs of the production, it stipulates the inspection methods and technical requirements of each stage in the quality inspection of the geographical condition survey results, and extends the traditional inspection and acceptance technology, and solves the key technologies that are badly needed in the first national geographic survey. This method develops an important role on the "process quality process, achievement acceptance inspection and achievement quality rechecking" in 31 provinces and 397 survey operation units. The third-party evaluation report co-issued by Chinese Society for Surveying, Mapping and Geoinformation and other units indicates that national geographical condition survey result "has had more than $97 \%$ of good rate and $99 \%$ of data accuracy rate and overall reliability". The technical achievements and promotion experience developed by this project can provide reference and foundation for the national special geographical condition monitoring under construction, normalized national geographical monitoring in the future, and quality control of other major mapping engineering projects.

\section{ACKNOWLEDGEMENTS}

This work is partly supported by National Science Foundation of China (grant No. 41671440).

\section{REFERENCES}

Chen, J. Y. (2014). Considerations on National Geographic Condition Investigation. Geospatial Information.

Cheng, P. F., \& Zhang, L. (2015). Talking about harvest of the quality control of National Geographic Condition Investigation, based on the result quality review. China Surveying and Mapping.

Li, D., Sui, H., \& Shan, J. (2012). Discussion on key technologies of geographic national conditions monitoring. Wuhan Daxue Xuebao, 37(5), 505-512.

Liu, Y. Y., \& Wu, S. Y. (2014) Key processes of quality control of land cover information collected in National Geographic Condition Investigation. Low Carbon World.

Yi, J. H., Meng, L. K., Xu, Q. L., \& Qiu, Y. F. (2017). Workload assessment model of quality inspection for surface cover products of geographical conditions census results. Science of Surveying \& Mapping.

Zhang, J. X., Zhao, Y. S., Luo, F. J., \& Dang, Y. (2017). Construction and Effect Analysis of Geographical Conditions Census Quality Control System. Bulletin of Surveying and Mapping.

Zhang, L., Cheng, P. F., Han, \& W. L. (2015). Investigations of Quality Evaluation Standard for National Surveying and Mapping Key Project Products. Bulletin of Surveying and Mapping. 